\title{
NATURE INDEX GLOBAL
}

\section{GLOBAL OVERVIEW}

High-level results from the Nature Index show three strong regions, but also reveal a more nuanced picture.

\section{FAVOURED COLLABORATORS}

Each region has a certain proportion of papers that are wholly authored by local researchers. The rest of the papers involve collaborators from other regions, but not always from those nearest to home. Note that each connecting arc assumes purely bilateral collaborations.

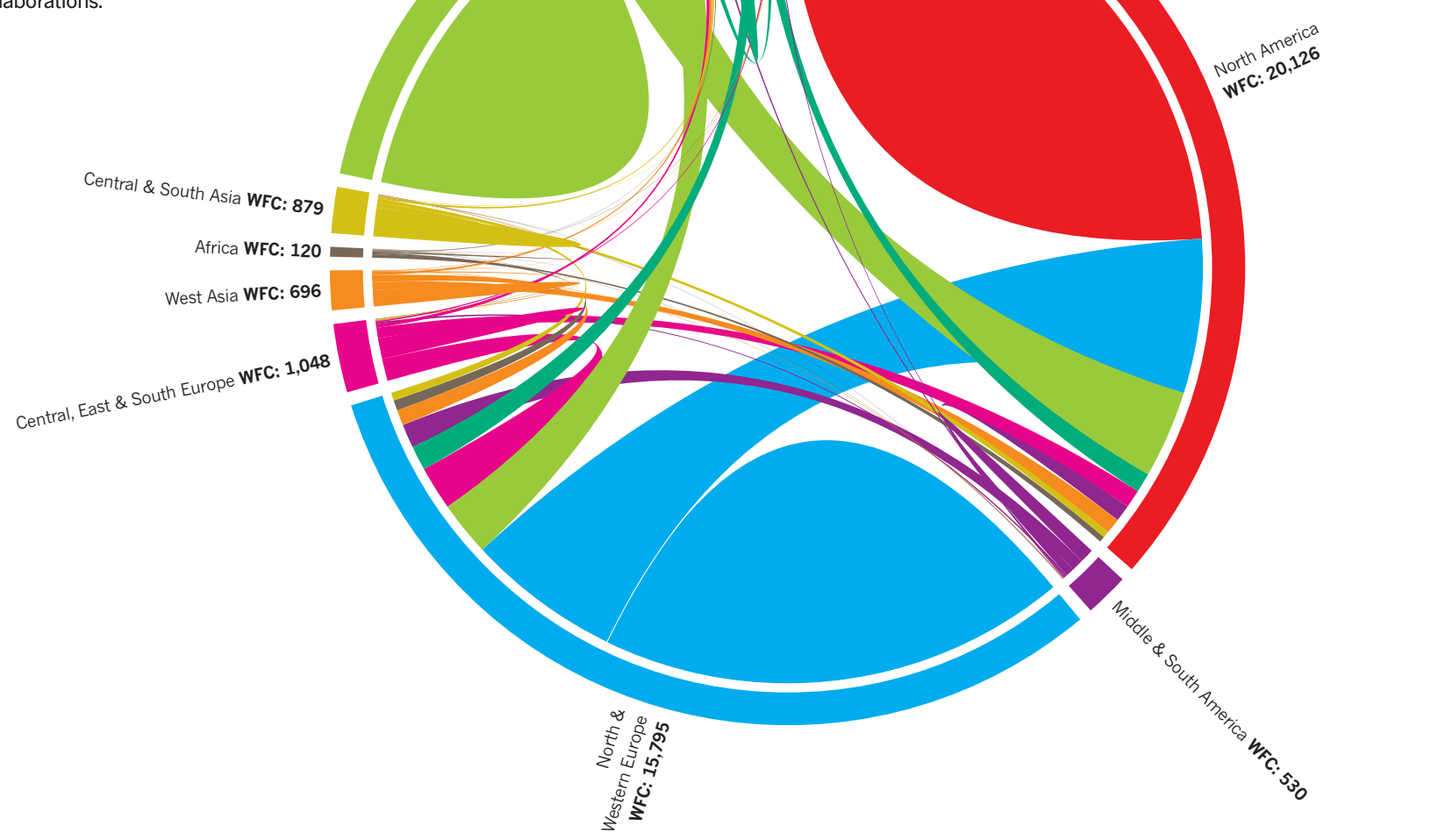

\section{FREQUENCY OF COLLABORATION}

The ratio of article count (AC) to fractional count (FC) gives a measure of the region's propensity to collaborate. A higher number means more collaborators from outside the region per paper.

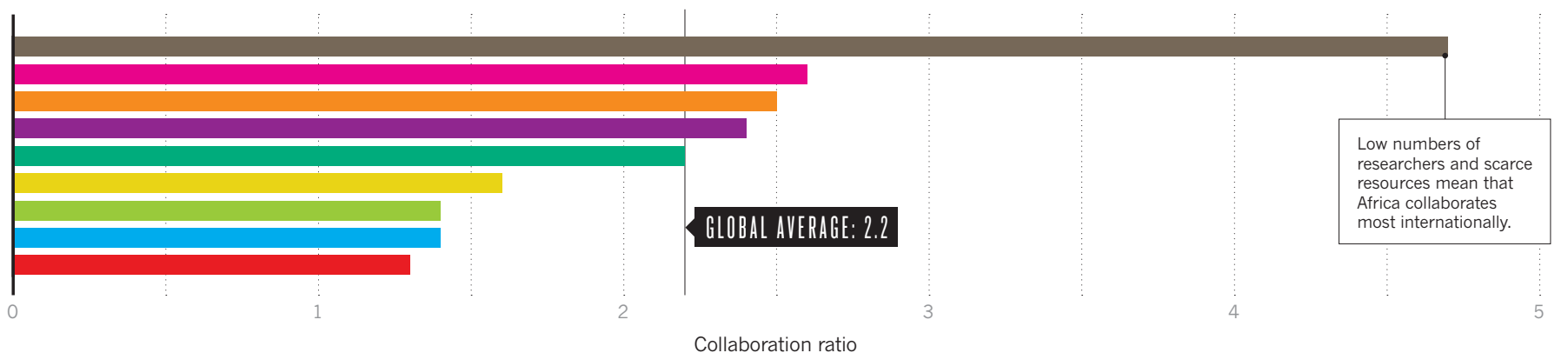




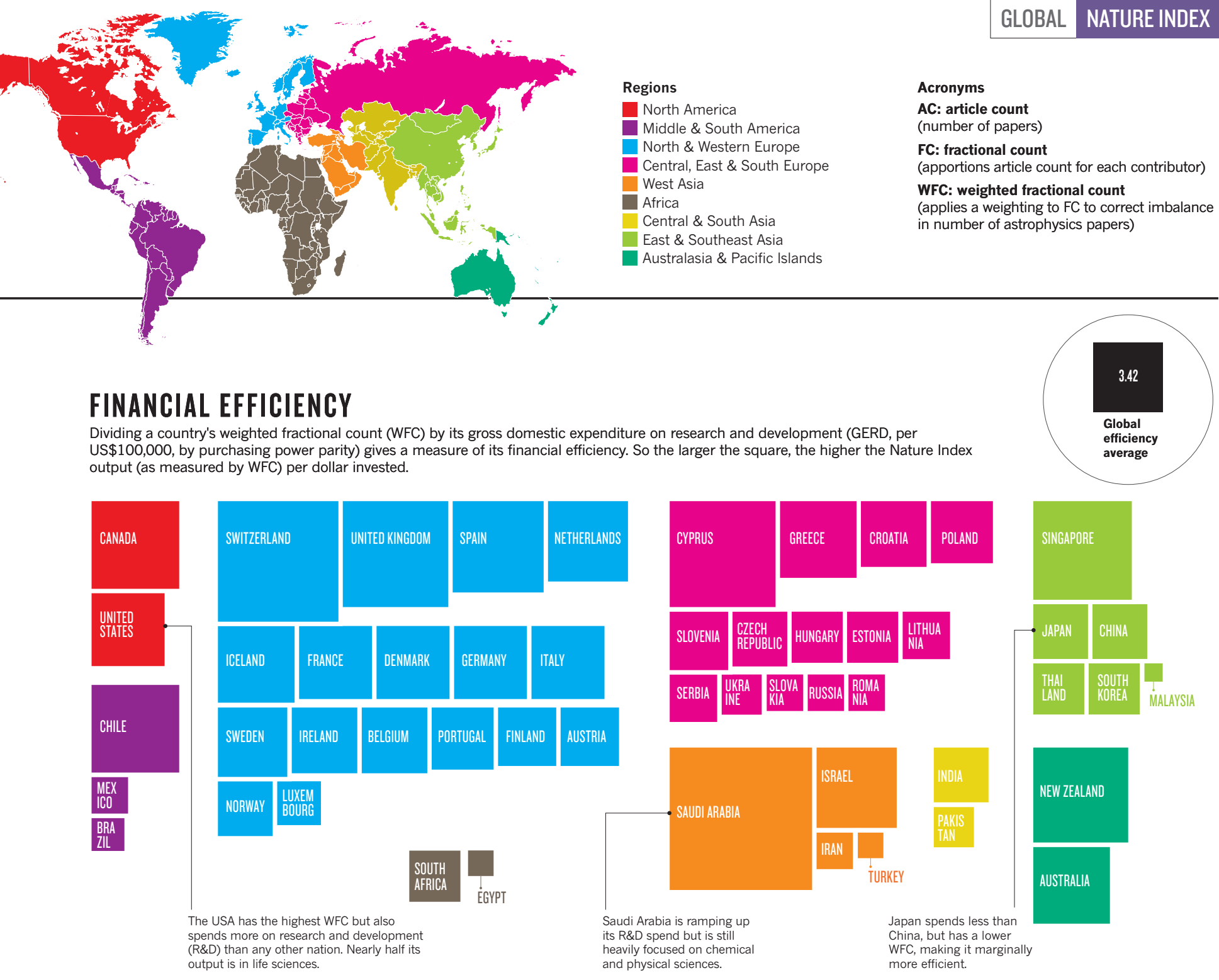

\section{SUBJECT STRENGTHS}

On a regional basis, North America has the highest WFC in three of the four subject areas. However, each region has a unique subject footprint.

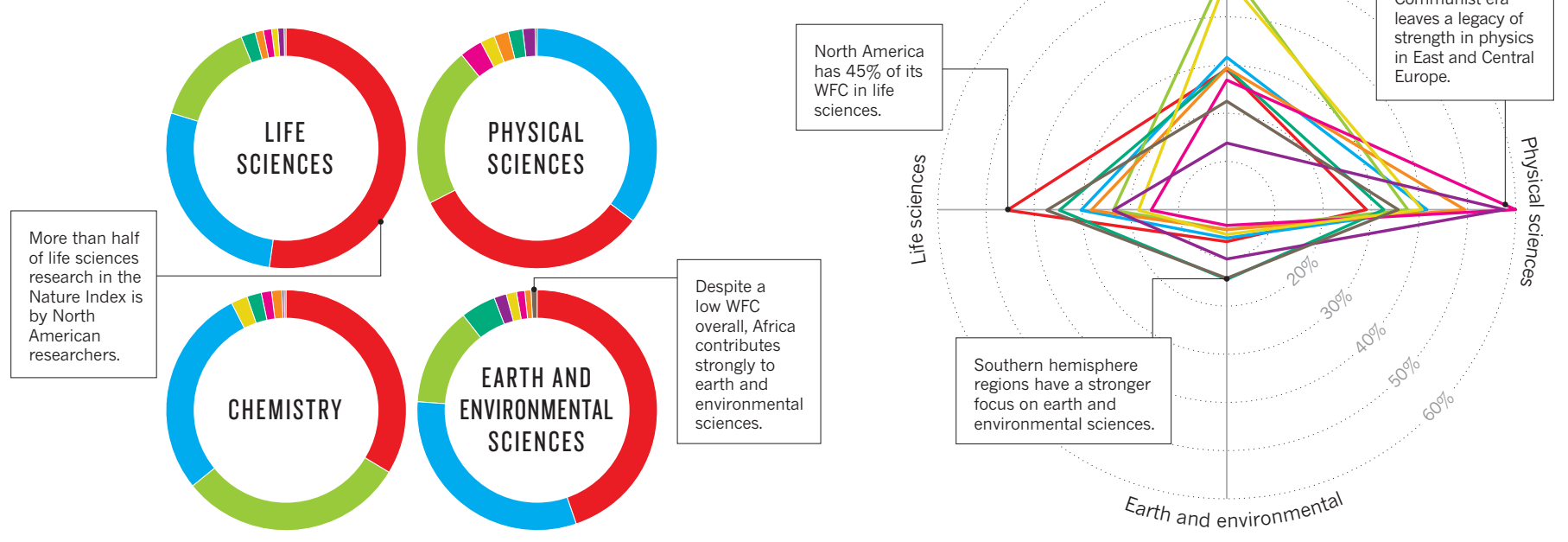

